\title{
The effect of growing conditions and pollination mode on the Lonicera caerulea berry mass
}

\author{
Irina $\mathrm{G}$. Boyarskikh* \\ Central Siberian Botanical Garden of the SB RAS Novosibirsk, 630090, Russia
}

\begin{abstract}
The berry mass of the blue honeysuckle plants of different environmental and geographical provenance was shown to be affected by the weather conditions at the time of the fruit setting and ripening. Pollination by defective pollen and by the pollen of closely-related species resulted in the decreased berry mass.
\end{abstract}

\section{Introduction}

The last decades have seen increased blue honeysuckle (subsec. Caeruleae Rehd., Lonicera genus, Caprifoliaceae Juss. family) cultivation in different countries with temperate climate. The major advantage of the species is ensured by its super-early ripening, as well as high contents of vitamin $\mathrm{C}$ and biologically active phenolic compounds [1].

The berry of blue honeysuckle represents an aggregate fruit, in which two juicy ovaries with 10-15 seeds each are surrounded by juicy and fleshy outer layer. The latter by its surface properties and development determines berry form and mass of different blue honeysuckle samples. The berry yield is an important component of the plant production [2]. Therefore the berry mass is regarded as an important characteristic of elite forms or varieties to be considered when making decisions about the introduction into culture.

The aim of the work was to study the variation of the fruit mass in samples of the three subspecies of Lonicera caerulea of different environmental and geographic provenance, as well as genetic origin, in relation to growing conditions and pollination modes.

\section{Material and methods}

The study was carried out on the experimental plot of the Central Siberian Botanical Garden of the Siberian Branch of the Russian Academy of Sciences $\left(54^{\circ} \mathrm{N}, 83^{\circ} \mathrm{E}\right.$, Novosibirsk, Russia) in the forest-steppe zone in the south of West Siberia under the continental climate with moderate heat and moisture resources. The data on the total precipitation and mean air temperature at the time of fruit setting were used to compare weather conditions [3].

The berry mass and seed number were studied under self- and cross pollination of the three blue honeysuckle cultivars: L. caerulea subsp. altaica (Pall.) Gladkova (syn. L. altaica Pall.) from the Rudny Altay region ('Salyut' and 'Galochka' cultivars), L. caerulea

\footnotetext{
* Corresponding author: irina_2302@ mail.ru
} 
subsp. venulosa (Maxim.) Worosh. (syn. L. edulis Turcz. ex Freyn) from Primoriye region in the Russian Far East ('Tomichka', 'Pamyati Gidzyuka', 'Vasyuganskaya', 'Bakcharskaya' and 'Parabel'skaya' cultivars), L. caerulea subsp. kamtschatica (Sevast.) Gladkova (syn. L. kamtschatica (Sevast.) Pojark. from the Kamchatka Peninsular ('Goluboe vereteno', 'Sinyaya ptitsa', 'Gerda', 'Zolushka', 'Roksana', 'Kamchadalka' cultivars). Statistical analysis was performed using Excel software.

\section{Results and discussion}

Analysis of berry mass variation over 10 years and its comparison with the average monthly temperature and total precipitation at the time of fruit setting revealed that berry mass depended on weather conditions (Fig.1). The berry mass of all studied blue honeysuckle samples displayed positive correlation with atmospheric precipitation at the time of fruit setting and ripening and negative correlation with air temperature averaged over the same period. The berry mass of L. caerulea subsp. venulosa from Primoriye showed the strongest correlation with total precipitation $(\mathrm{r}=0.60 \div 0.92)$, whereas $L$. caerulea subsp. kamtschatica of Kamchatka provenance and L. caerulea subsp. altaica of Rudny Altai provenance showed weaker correlation respectively $(\mathrm{r}=0.38 \div 0.62)$ and $(\mathrm{r}=0.18 \div 0.48)$. Some samples of $L$. caerulea subsp. venulosa and $L$. caerulea subsp. kamtschatica were found to respond weakly to changes in air temperature $(\mathrm{r}=-0.15 \div-0.19)$. The berry mass of L. caerulea subsp. altaica 'Galochka' showed no correlation $(\mathrm{r}=0.18)$ with atmospheric precipitation.

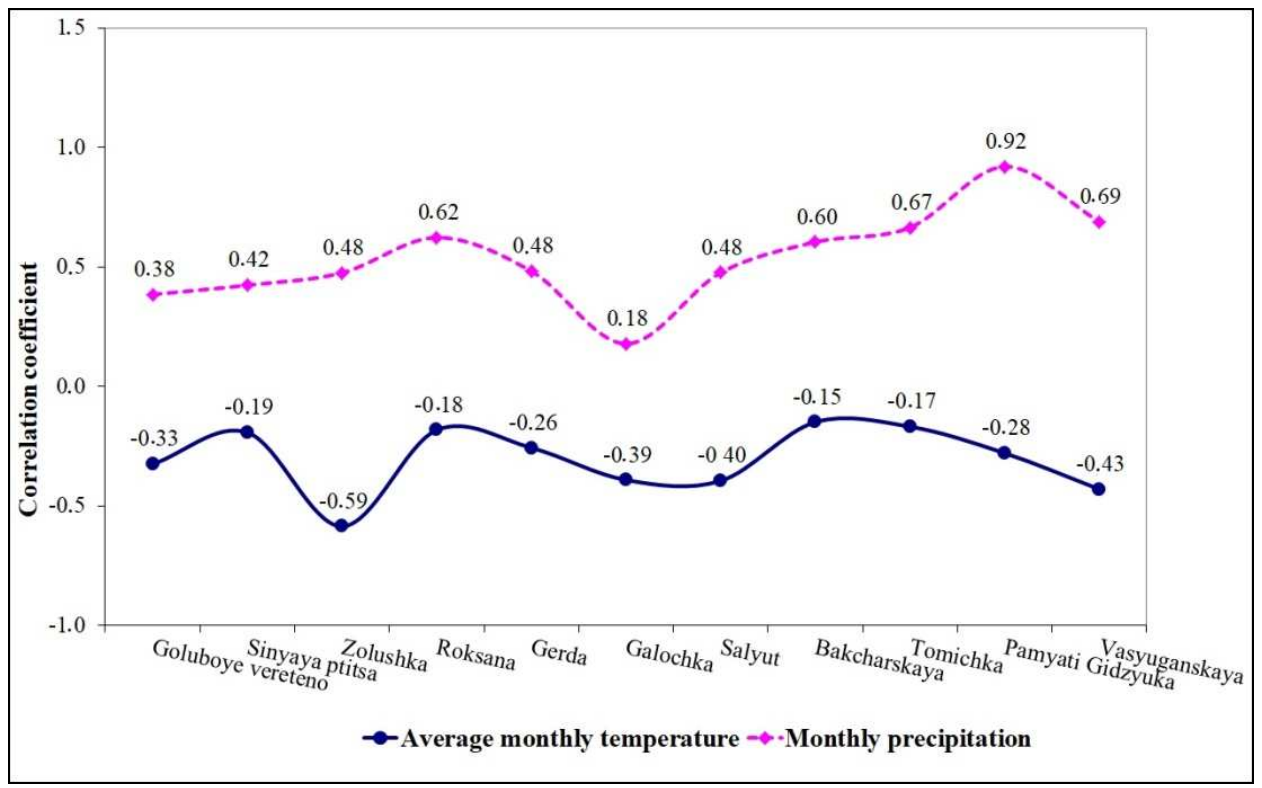

Fig.1. Correlation between a berry mass and weather conditions during the period of fruit setting and ripening.

Comparative evaluation of the mass of 100 fruits produced by 'Tomichka' cultivar showed that on the irrigated plot the mass reached $87 \mathrm{~g}$, whereas on the non-irrigated plot it was $75 \mathrm{~g}$. Thus additional water supply increased the blue honeysuckle berry mass by $14 \%$.

The berry mass was also found to vary strongly $(\mathrm{V}=25 \%)$ due to pollination mode (Fig.2). According to our earlier results [4] the fruit mass of 'Zolushka' cultivar ranged $0.39-0.84 \mathrm{~g}$. The biggest fruits $(0.84 \mathrm{~g})$ were produced by open pollination; the fruits 
produced by pollination from 'Tomichka' and 'Pamyati Gidzyuka' were close in mass $(0.82$ and $0.76 \mathrm{~g}$, respectively). The smallest fruits $(0.9 \mathrm{~g})$ were obtained by self-pollination, as well as in such combinations as 'Zolushka' $\mathrm{x}$ 'Salyut' $(0.44 \mathrm{~g})$, 'Zolushka' $\mathrm{x}$ 'Goluboe vereteno' $(0.51 \mathrm{~g})$ and 'Zolushka' $\mathrm{x}$ 'Berel' $(0.53 \mathrm{~g})$. This was most likely due to the poor quality of the pollen produced by 'Salyut' and 'Berel' cultivars [4], as well as due to partial incompatibility with the closely related 'Goluboe vereteno' cultivar [4].

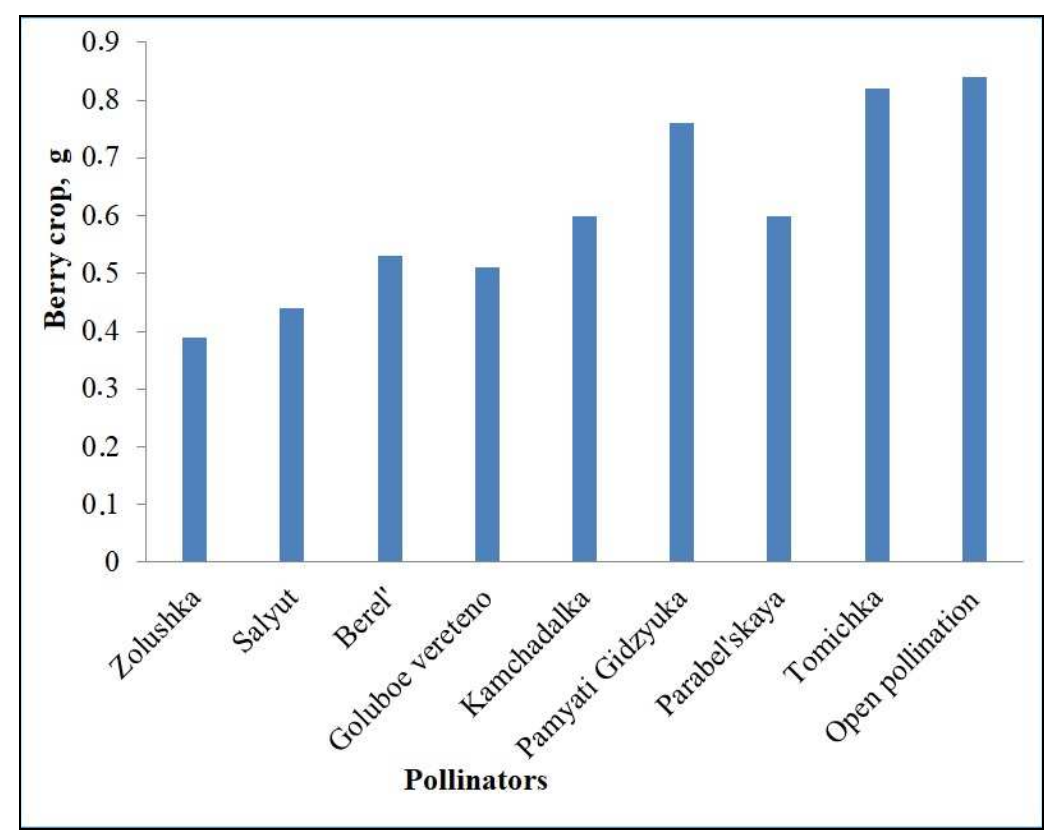

Fig. 2. Relationship between a berry mass of 'Zolushka' cultivar and its pollinators (as averaged over 3 years)

Relationship between berry mass and the number of full-fledged set seeds showed close positive correlation $(r=0.73 \div 0.98)$ for most of the cultivars studied, both by stochastic and cross pollination modes. Poor seed development had weak or moderate effect on the fruit mass. However, beside this, some pollination variants showed weak $(\mathrm{r}=0.11)$ or moderate $(\mathrm{r}=0.31 \div 0.67)$ correlation.

It is possible that berry mass was also affected by other growing conditions, and in particular by mineral nutrition, which can stimulate synthesis of phytohormones, affecting fruit development and growth irrespective of the set seeds.

\section{References}

1. A. B. K. H De Silva, H. P. V. Rupasinghe, Journal of Food Composition and Analysis 88 (2020)

2. M. N. Plekhanova, Acta Horticulturae, 538 (2000)

3. The Meteorological Data Base with daily resolution. URL:http://rp5.ru/

4. I. G. Boyarskikh, Agricultural biology, 52 (2017) 